\title{
Language issues in mathematics word problems for English learners
}

\section{Introduction}

This paper describes language issues in mathematics word problems for English language learners (ELLs). We first summarize research relevant to the linguistic complexity of mathematics word problems from studies in mathematics education, reading comprehension, and vocabulary. Based on that research, we make recommendations for addressing language complexity and vocabulary in designing word problems for instruction, curriculum, or assessment. We then use examples of word problems ${ }^{1}$ to illustrate how to apply those recommendations to designing or revising word problems and creating supports for students to work with word problems.

\section{Summary of relevant research on language issues in mathematics}

This section contextualizes recommendations for the design of word problems and support for word problem instruction for ELLs, using research on language issues in mathematics. In reviewing the relevant research on language and mathematics, we focused on research specific to the domain of mathematics and word problems in particular.

\footnotetext{
1 These word problems are sample released items for the U.S. assessment created by the Smarter Balanced Assessment Consortium. The Smarter Balanced Assessment Consortium (SBAC) is a standardized test consortium that created Common Core State Standards-aligned tests ("adaptive online exams") to be used in several states in the United States. The Common Core State Standards Initiative is an educational initiative from 2010 that details what K-12 students throughout the United States should know in English language arts and mathematics at the conclusion of each grade.
} 


\subsection{Research on language issues in mathematics word problems}

There are multiple uses of the terms language in mathematics education research. Some interpretations of the phrases "language in mathematics" or "mathematical language" reduce their meaning to single words or the proper use of technical vocabulary. In contrast, we ground this chapter in research in mathematics education that provides a more complex view of mathematical language. Such work (e.g., Pimm, 1987) provides a view of mathematical language as not only specialized vocabulary-new words and new meanings for familiar words-but also as extended discourse that includes syntax and organization (Crowhurst, 1994), the mathematics register (Halliday, 1975), and discourse practices (Moschkovich, 2007).

Researchers in mathematics education have examined many topics related to mathematics and language, some of them relevant to designing word problems used with ELLs, for example, mathematical texts (O'Halloran, 2005), words with multiple meanings or polysemy (Pimm, 1987), and differences between mathematical registers at school and at home (Walkerdine, 1988). One contribution that is especially relevant to word problems is a shift from seeing the mathematics register as merely technical mathematical language. The mathematics register should not be interpreted as merely a set of words and phrases particular to mathematics. The mathematics register includes styles of meaning, modes of argument, and mathematical practices. It also has several levels of complexity that go beyond the word or phrase level to include background knowledge level and complexity at the sentence or paragraph level.

The following word problem illustrates how the mathematics register is not simply about vocabulary specific to mathematics and involves more than only the word level:

A boat in a river with a current of $3 \mathrm{mph}$ can travel 16 miles downstream in the same amount of time it can go 10 miles upstream. Find the speed of the boat in still water.

The complexity involved in making sense of this word problem is not at the level of technical mathematical vocabulary, but lies principally in the background knowledge (Martiniello \& Wolf, 2012) for understanding and imagining the context or situation for the problem. In this case, the reader needs to imagine and understand that there is a boat traveling up and down a river, that the speed was measured in still water (presumably a lake), and that the speed of the boat increases (by the speed of the current) when going downstream, and decreases (by the speed of the current) when going upstream. The language complexity lies not in understanding 
mathematical terms, but having the background knowledge to imagine the situation. A glossary for non-mathematical words such as upstream, downstream, and the phrase in still water would certainly help. However, also notice that much of the language complexity is not at the word level, but at the sentence and paragraph levels, in the use of the passive voice without an agent and in the multiple subordinate clauses and nested constructions (Cook \& MacDonald, 2013).

Another contribution from mathematics education work relevant to mathematics word problems is that we know there are international differences in the meaning of some mathematical terms. For example, the definitions of trapezium and trapezoid (a quadrilateral with no sides parallel) are often interchanged. In Spanish, "The word trapezoid is reserved for a quadrilateral without any parallel sides, whereas trapezium is used when there is one pair of parallel sides (This is opposite to American English usage)” (Hirigoyen, 1997: 167).

\subsection{Research on language complexity of mathematics word problems in assessments}

The research on word problems on assessments is relevant to considering the language complexity in word problems. According to Abedi (2002), linguistic complexity of assessment word problems unrelated to the content being assessed may at least be partly responsible for the performance gap between ELLs and non-ELLs, and linguistic complexity of assessment word problems may invalidate achievement on tests. In particular, Shaftel et al. (2006) found that fourth graders had difficulty with vague words, complex verbs (verbs with three or more words, e.g., had been going), pronouns, prepositions, and mathematical vocabulary. The greater the number of linguistic elements, the more difficult the word problem proved to be. Grade 7 students found it hard to understand mathematical vocabulary and comparative terms (greater than, less than). Overall, unfamiliar words, rarely used vocabulary, and passive voice hinder comprehension (Abedi \& Lord, 2001).

Abedi (2009) studied several supports (computerized tests, a pop-up glossary, a customized English dictionary, extra testing time, and small-group testing). The dictionary was customized and did not include any content-related vocabulary. He found that all the supports made a significant difference for ELL students for the more linguistically complex word problems. Another study (Sato et al., 2010) used an original and modified version ${ }^{2}$ and found that linguistically

2 This study used the Grade 8 National Assessment of Educational Progress (NAEP) and the Grade 7 California mathematics assessment. 
modified versions more reliably measured mathematical proficiency of students labeled as ELL or Non-English Proficient (NEP) than the original format and linguistic modification did not alter the targeted math constructs being assessed.

Martiniello (2008) found that understanding word problems that involve polysemous words can be challenging for ELLs. Polysemous words are words with different meanings or connotations, depending on the context provided by the text or discourse. Martiniello gave the following example: "Find the amount of money each fourth-grade class raised for an animal shelter using the table below." The word raised here refers to collecting funds. Other meanings are "raise your hands," "raise the volume," "raising the rent," or "receiving a raise." Martiniello found that ELLs tended to interpret the word raise as "increase" and did not understand the connotation of raise in fund raising.

Martiniello and Shaftel both found that fourth-grade students struggled with specific categories of vocabulary. These included words with multiple meanings, slang or conversation words, and words learned in an English-speaking home (Martiniello, 2008; Shaftel et al., 2006). Martiniello concluded, "It is important to distinguish between school and home related vocabulary as a potential source of differential difficulty for ELLs." She suggests that since ELLs learn English primarily at school, school-related words (student, pencil, ruler, school, day, book, etc.) are likely to be more familiar than words related to the home (her examples included raking leaves, chore, washing dishes, vacuum, dust, rake, and weed). Martiniello's general recommendations for word problems include avoiding unnecessary linguistic complexity not relevant to mathematics, refining linguistic complexity measures so they include issues that are specific to ELLS (e.g. home vocabulary, polysemy, familiarity), and, for assessments, including thorough review by experts on ELLs.

\subsection{Summary of research on the language of mathematics word problems}

The following key understandings from research contribute to recommendations for how to design, revise, or support mathematics word problems when working with ELLs. The language features of word problems documented as problematic for ELLs are at three levels: Cultural (background level), syntactic (sentence and paragraph level), and lexical (word and phrase level). All three levels should be considered in designing mathematics word problems for curriculum materials, in designing assessment problems, and when considering supports such as glossaries. 
A crucial aspect of word problems is the background knowledge and cultural references necessary for understanding the setting of a word problem. Since it is not possible to predict what settings, context, or background knowledge all students share, it is important to provide some support for any setting described in an item. The syntactic level involves the way sentences are put together. Several challenging aspects of mathematics word problems include the use of the passive voice without an agent, multiple subordinate clauses, nested constructions, and long noun phrases. The lexical level involves unfamiliar words, unfamiliar phrases, and unfamiliar connotations of words with multiple meanings (polysemy).

Vocabulary that is specific to mathematics is not the only source of difficulty. Since the language complexity of mathematics word problems and the language complexity issues for ELLs are not all necessarily at the word level, the overall recommendation is that the design of word problems and the guidelines for glossaries should focus on cultural and syntactic levels, in addition to the lexical level.

\section{Summary of relevant research on reading comprehension}

This section contextualizes recommendations for the design of word problems and support for word problem instruction for ELLs. In reviewing the relevant research on vocabulary and reading, we focused on a broad view of reading comprehension and word knowledge, not constrained by the domain of mathematics. The following key understandings from research on reading comprehension and vocabulary can contribute to recommendations.

\subsection{Background knowledge}

Background knowledge plays a large role in understanding text and making inferences about a word's meaning. Research in the last 40 years has shown that language comprehension requires knowledge of the world as well as knowledge of the language (McNamara et al., 1991). Reading comprehension depends on interaction between the reader (e.g., background, knowledge, abilities, and experience), the activity (e.g., instruction, grouping, purpose), and the text (e.g., genre, structure, words), embedded within a sociocultural context (RAND reading study group; Snow, 2002). "Text can be difficult or easy depending on factors inherent in the text, on the relationship between the text and the knowledge 
and abilities of the reader, and on the activities in which the reader is engaged" (RAND: 14). Within an individual text, such as a word problem, the vocabulary load and linguistic structure interact with the readers' knowledge during the comprehension process. Comprehension is affected when there is a mismatch between the text and student's knowledge and experience. A synthesis of research on background knowledge and assessment with ELLs revealed that underdeveloped background knowledge or lack of background knowledge hinders performance on all types of assessments, including word problems (August \& Shanahan, 2006).

\subsection{Words have multiple meanings}

Multiple meanings for words are a common source of confusion for students. Words are the cornerstone of effective communication, but work knowledge is complex and multifaceted (Anderson \& Nagy, 1991; Beck \& McKeown, 1991; Nagy \& Scott, 2000). In addition to multiple meanings, words are often abstract, are used in idioms, vary according to register, and differ according to context.

Anderson et al. (1976) propose, "A word does not have $a$ meaning, but has, rather, a family of potential meanings" (p. 667). The more frequent a word is in English, the more likely it is to have multiple meanings (Nagy, 2009). For instance, a round of golf, singing in a round, rounding up numbers, and a round shape are all acceptable uses for the word round. The meaning of individual words (and phrases) must be inferred from context and is nuanced by that context, even if it is a familiar word (Nagy \& Scott, 2000).

\subsection{Word frequency}

Most of the words in English, particularly academic words, occur infrequently. In a 17.5-million-word corpus from K-12 schoolbooks (Zeno et al., 1995), the frequency distribution shows that a core set of 5,600 words accounts for almost $80 \%$ of the words. The other $20 \%$ are over 150,000 unique words, most of which are seen less than once per million words of text (Nagy \& Hiebert, 2011). Given this distribution, it is likely that many ELLs will not know or recognize infrequent words. On average, ELLs at fourth- and fifth-grade score more than two grade levels below their native English-speaking peers in English vocabulary knowledge and tend to use high-frequency words for communication rather than low-frequency vocabulary (Manyak, 2012). 


\subsection{Verbs and nouns}

Verbs are harder to learn than nouns. Young children learn concrete nouns before verbs in part because verbs have a less transparent relationship to the perceptual world (Gentner, 1982). For concrete nouns, the mapping between a word and its referent is tangible. For verbs, this mapping depends on the language used, and the way that information is captured by verbs varies across languages (Gentner, 2006). For instance, English verbs include manner of motion (e.g., the little bird hops out of the cage) while Spanish typically includes path of motion, and not manner (e.g. El pajarito sale de la jaula dando saltitos-The little bird leaves from the cage giving hops) (Negueruela et al., 2004: 118). Note that the word exit could have been used instead of leaves from to avoid the propositional verb.

\subsection{Using high-frequency words and shorter sentences is not the solution}

The use of high-frequency words and shorter sentences may make a text more difficult to read rather than easier. Abedi et al. (2004), in a thorough review of assessment supports for ELLs, established that minor changes in the wording or the syntactic complexity of mathematics problems can affect student performance and recommend using straightforward, uncomplicated language when developing word problems for assessments. While this makes sense as a general rule, substituting more familiar words for more precise, less frequently seen, words might also be problematic. Since high-frequency words are more likely to have multiple meanings (Nagy, 2009), this needs to be factored into decisions about word use.

Syntactical simplification is also problematic, as shortening sentences by eliminating words that establish connective relationships (because, therefore, etc.) can make text harder to read rather than easier (Davidson \& Kantor, 1982). In a study with Puerto Rican students learning English as a second language, researchers found that eighth-grade students' comprehension benefited from longer sentences that showed relationships rather than from choppy sentences with simple syntax. Thus, sentences like, "If the manufacturer and the market are a long distance apart, then it can be a big expense for the manufacturer to get goods to market" were easier to understand than several shorter sentences like, "Manufacturers must get goods to market. Suppose that the manufacturer and the market are a long distance apart. This can be a big expense” (Blau, 1982: 518). 


\subsection{Other factors relating to word recognition}

Two different studies indicate that both word frequency and the age of acquisition of a word are features that influence the ease or difficulty of word knowledge, and the second study also reported word length, number of syllables, and concreteness or imageability as significant factors (Hiebert et al., 2019). Age of acquisition captures when children can typically understand or use a word in oral language, and thus relates to familiarity with the word. Concrete words, words that can be easily thought of as a picture or an image, are easier than abstract words, and imageability interacts with both the complexity of sentences and word familiarity to influence word recognition (Mesmer et al., 2012). These additional factors should also be considered in choosing words for word problems.

Some words are more easily decoded because their spelling pattern maps onto recognizable phonetic patterns (Adams, 1990). For Spanish speakers, the use of cognates with a similar meaning may facilitate word recognition (Nagy et al., 1993). For instance, rotation/ rotación are cognates. Using rotation in a word problem instead of the word spin or flip would help those Spanish-speaking students who recognize this relationship. However, the use of complex or unfamiliar orthographic patterns (e.g., bouquet, answer, souvenir) can prove challenging, for non-ELLs as well as ELLs (Peregoy \& Boyle, 2000).

\subsection{Definitions}

Definitions are often not student friendly. Using typical definitions to understand the meaning of unknown words is a difficult metalinguistic task (McKeown, 1993; Miller \& Gildea, 1987; Scott \& Nagy, 1997). The conventions of standard definitions are largely the result of the need to conserve space in their printed form (Landau, 1984). Definitions are "even more decontextualized, more terse, and less like oral language than most of the written language to which children have been exposed" (Scott \& Nagy, 1997: 187). Graves et al. (2012) suggest that studentfriendly definitions are "longer, often written in complete sentences, phrased in ways that are as helpful as possible to second-language learners, and do not include words more difficult than the word being defined. Also, sentences that give an example of the thing named can be a useful add-on to a student friendly definition" (pg. 58). They suggest that providing a visual that represents a word, and a sentence that explains how it represents the word, may be crucial for helping ELLs understand the word's meaning. 


\section{Implications and recommendations for writing word problems}

This set of key insights from research can be used to help guide the design, modification, and support of word problems and help determine which words should go into glossaries. Below we summarize recommendations for addressing three levels in the language of mathematics word problems:

a) Cultural level: When choosing situations for word problems, background and cultural knowledge is crucial for understanding the context for word problems. Short explanations of the setting or context are often necessary. Since it is not possible to predict what settings, context, or background knowledge all students bring or share, it is important to use common settings, such as school, and to provide short explanations of any setting described in an item.

b) Syntactic level: When considering syntax, as a rule, it is best to keep sentence structure clear and straightforward. However, connective words in longer sentences that help students understand relationships should not be eliminated if they facilitate meaning. Long sentences should be broken into shorter, less complex sentences only if the shorter sentences make the meaning clearer. Avoiding complex noun and verb phrases, using an active voice with an agent, reducing nested constructions and subordinate clauses, using pronouns with clear references, and using sentences with a clear subject would also help students process the problems more easily.

c) Lexical level: When choosing words for word problems it makes sense to avoid the type of words that may cause comprehension problems for ELLs. To facilitate word recognition and understanding, first acknowledge that word meanings are flexible and variable, and that word problems often include polysemous words. If multiple meanings might confuse students, it might be worthwhile to use another word. When there is a choice between words, it makes sense to choose imageable words and cognates. If that isn't possible, a glossary and the context should provide sufficient information to make the word meaning clear.

Infrequent or unusual words, words with complex spellings, vague words, abstract words, idioms, and colloquial or slang phrases should all either be replaced or glossed. Using words in a students' oral language, cognates, concrete words, and easily decodable words will help focus the assessment on the mathematics instead of English proficiency. Uncommon verbs, particularly those that are central to comprehending a word problem, should be glossed for most problems. 
Glossaries can be a useful resource, if they are well written, provide visuals, and explain the context of the word. Glossaries are particularly important for polysemous words, multiword phrases (e.g., standard deviation), satellite or phrasal verbs known to be problematic for ELLs (e.g. look up, clean up, turn off, bring up, etc.); regionalisms (e.g., bag/sack, soda/pop), and mathematical terms that differ across countries (e.g., trapezoid).

\subsection{Designing a glossary}

The definitions provided in a glossary should try to explain words in complete, easy-to-read sentences. There is no need to use the terse, convoluted language forms found in typical dictionaries. Example sentences should be used as needed. A picture is often the quickest way to convey the meaning, particularly for concrete nouns. It is much easier to show a picture of a kangaroo than to try to explain what a kangaroo is in words. Since imageability of words can aid recognition and understanding, it makes sense to make those images available to students.

The following are a few guidelines for identifying terms for an Englishlanguage glossary:

a) Background knowledge: Provide short explanations or descriptions of the setting or context that may not be familiar to all students; use visuals and pictures to illustrate setting and context.

b) Syntactic level: Write in a clear, straightforward, and cohesive manner; make relationships within the word problem transparent.

c) Lexical level: Use visuals and pictures to illustrate words, particularly concrete nouns; provide glossaries for unfamiliar words, unfamiliar phrases, and unfamiliar connotations of words with multiple meanings (polysemous words); replace words, or provide glossaries for abstract words and words with unusual spelling patterns; provide glossaries for verbs, particularly those that are central to comprehending and completing the word problem.

\section{Examples}

Several of the word problems we use below as examples illustrate overlapping issues. For instance, infrequent vocabulary is often correlated with lack of background knowledge. However, we have created these revisions from real items, and grouped them as examples of areas of concern. 


\subsection{Cultural (background knowledge) examples}

\section{Example 1 - Original}

A company purchases $\$ 24,500$ of new computer equipment. For tax purposes, the company estimates that the equipment decreases in value by the same amount each year. After 3 years, the estimated value is $\$ 9,800$.

Which of the following is an explicit function that gives the estimated value of the computer equipment $\mathrm{n}$ years after purchase?

It is unlikely that many high school students know about paying taxes and depreciation.

\section{Example 1 - Revised}

A company buys $\$ 24,500$ of new computer equipment. The company estimates that the equipment decreases in value by the same amount each year. After 3 years, the estimated value is $\$ 9,800$.

Which of the following is an explicit function that gives the estimated value of the computer equipment $n$ years after purchase?

Since paying taxes and depreciation are complex ideas to explain, it might be easiest to eliminate the phrase "For tax purposes." This also eliminates the need to explain this complex idea and doesn't affect the word problem. Replace purchases with buys, a more familiar and frequently used word.

Glossary: Estimate-to guess an answer close to the correct value.

\section{Example 2 - Original}

Ms. Olsen is having a new house built on Prospect Road.

She is designing a sidewalk from Prospect Road to her front door.

Ms. Olsen wants the sidewalk to have an end in the shape of an isosceles trapezoid, as shown.

The contractor charges a fee of $\$ 200$ plus $\$ 12$ per square foot of sidewalk. Based on the diagram what will the contractor charge Ms. Olsen for her sidewalk?

The idea of having a contractor and designing a sidewalk may be unfamiliar to many students. Charges is a polysemous word.

\section{Example 2 - Revised}

Ms. Olsen wants her new house to have a new sidewalk that goes from the road to her front door. But, she doesn't want it to have straight lines. Instead, she wants the sidewalk to end in the shape of an isosceles trapezoid, as shown.

The builder charges a fee of $\$ 200$ plus $\$ 12$ per square foot of sidewalk. Based on the diagram what will the builder charge Ms. Olsen for her sidewalk? 
This revised version provides more context more clearly, without the passive voice or the use of unfamiliar terms and puts charges a fee in a glossary.

Glossary: Charges a fee-when someone charges a fee, they are asking the other person to pay that much money.

\subsection{Syntactic examples}

\section{Example 3 - Original}

Jason uses a balance scale to measure the weight of objects. Each of the objects is the same size but has a different weight. Four of the objects have their weights labeled and one does not. Jason is trying to find the weight of the object that is not labeled. He performs the two experiments shown below.

Which could be the weight of the object without the label?

The phrase, "Which could be" uses the conditional tense serves no real purpose and could confuse students. An additional concern is that the word object is generic, polysemous, and abstract, and perform is also polysemous.

\section{Example 3 - Revised}

Jason uses a balance scale to measure the weight of bricks. Each of brick is the same size but has a different weight. Four of the bricks have their weight labeled and one does not. Jason is trying to find the weight of the brick that is not labeled. He does the two experiments shown below.

What is the weight of the brick without the label?

The word object could be easily replaced with a word that is more concrete and imageable, like brick. A word like brick, with a visual image in the glossary, would be more familiar and accessible. The question without the conditional tense is more straightforward and easier to comprehend.

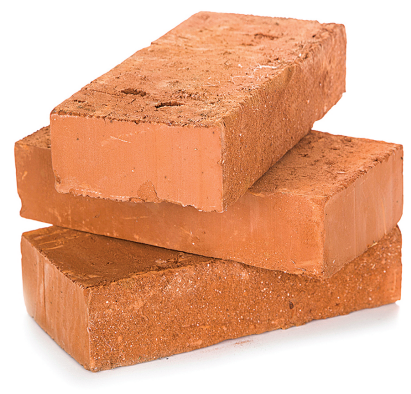

Fig. 1: Visual image for the word brick in Example 3. (Image courtesy of iStockphoto | vladakela) 


\subsection{Lexical examples}

\section{Example 4 - Original}

A giant gumball machine has the following qualities: It can hold no more than 1,000 gumballs.

- Exactly $7 / 40$ of the gumballs are blue.

- Exactly 4/21 of the gumballs are red.

- There are more white gumballs than blue gumballs.

- There are fewer white gumballs than red gumballs. Which is a possible number of white gumballs in the giant gumball machine?

\section{Infrequent words and multiple meanings}

While the word gumball is a concrete noun, it is also a low-frequency word in English. The word qualities and its singular form quality have multiple meanings. Students may confuse this sense of the word with the sense that relates to a grade of excellence (e.g., high quality).

\section{Example 4 - Revised}

A giant gumball machine can hold no more than 1,000 gumballs. Out of those 1,000 gumballs . .

- Exactly $7 / 40$ of the gumballs are blue.

- Exactly 4/21 of the gumballs are red.

- There are more white gumballs than blue gumballs.

- There are fewer white gumballs than red gumballs. Which is a possible number of white gumballs in the giant gumball machine?

Rewording the sentence to eliminate qualities reduces confusion. Adding a link to a picture of a gumball machine in a glossary, or to the item itself, and defining it in a glossary help students access the meaning.

Glossary: A giant gumball machine is a tall machine that gives out brightly colored balls of sugar-coated chewing gums in exchange for coins. 


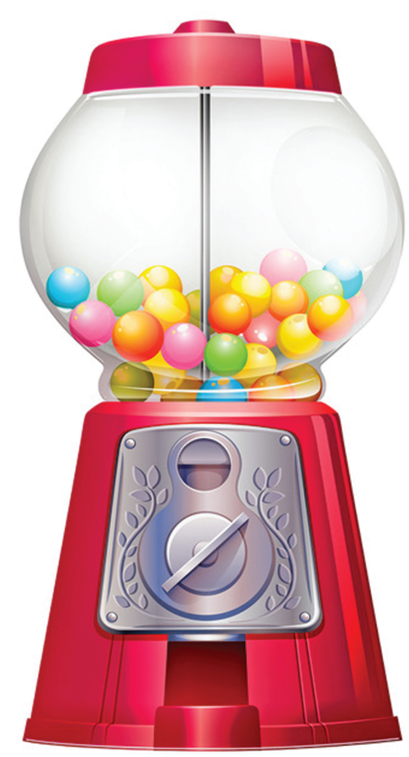

Fig. 2: Visual image for the phrase gumball machine in Example 4.

\section{Example 5 - Original}

Cara makes scarves in different sizes.

The first scarf has 12 stripes and 5 tassels.

The second scarf has 5 stripes and 8 tassels.

The spelling pattern of scarves and scarf is irregular and the word tassels is infrequent. It is also unlikely that tassels is a word in students' oral vocabulary.

\section{Example 5 - Revised}

Cara makes pillows in different sizes.

The first pillow has 12 stripes and 5 buttons

The second pillow has 5 stripes and 8 buttons.

A better alternative would be to change tassels to more familiar, imageable words like bedspread, pillows, or bookmarks that could have buttons, beads, or stickers. Although these are common words, a picture can facilitate comprehension. 


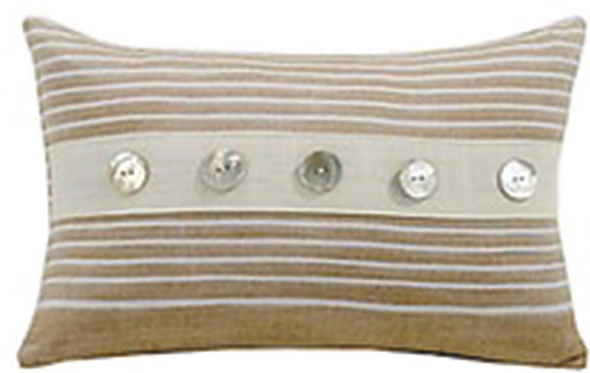

Fig. 3: Visual image for the word pillow in Example 5.

\section{Example 6 - Original}

The noise level at a music concert must be no more than 80 decibels $(\mathrm{dB})$ at the edge of the property on which the concert is held.

Melissa uses a decibel meter to test whether the noise level at the edge of the property is no more than $80 \mathrm{~dB}$.

- Melissa is standing 10 feet away from the speakers and the noise level is $100 \mathrm{~dB}$.

- The edge of the property is 70 feet away from the speakers.

- Every time the distance between the speakers and Melissa doubles, the noise level decreases by about $6 \mathrm{~dB}$.

Rafael claims that the noise level at the edge of the property is no more than $80 \mathrm{~dB}$ since the edge of the property is over 4 times the distance from where Melissa is standing. Explain whether Rafael is or is not correct.

The concept of a decibel is highly specific and the word is a low-frequency English word. Understanding the meaning of this word is central to understanding the word problem. In addition, speakers and speaker have multiple meanings, and could be interpreted as human speakers if the reader doesn't know this context. 


\section{Example 6 - Revised}

Decibels $(\mathrm{dB})$ are used to measure noise levels. The law says that the noise level at a music concert must be no more than 80 decibels at the edge of the property where the concert is held. Melissa uses a decibel meter to measure the noise level at the edge of the property.

- When Melissa is standing 10 feet away from the sound speakers, the noise level is $100 \mathrm{~dB}$.

- The edge of the property is 70 feet away from the speakers.

- Every time the distance between the speakers and Melissa doubles, the noise level decreases by about $6 \mathrm{~dB}$.

Rafael claims that the noise level at the edge of the property is no more than $80 \mathrm{~dB}$ since the edge of the property is over four times the distance from where Melissa is standing. Explain whether Rafael is or is not correct.

This revision adds context to the word problem and defines what a decibel and a decibel meter is within the item. It also disambiguates the word speaker. The addition of a picture of speakers in a glossary would also help.
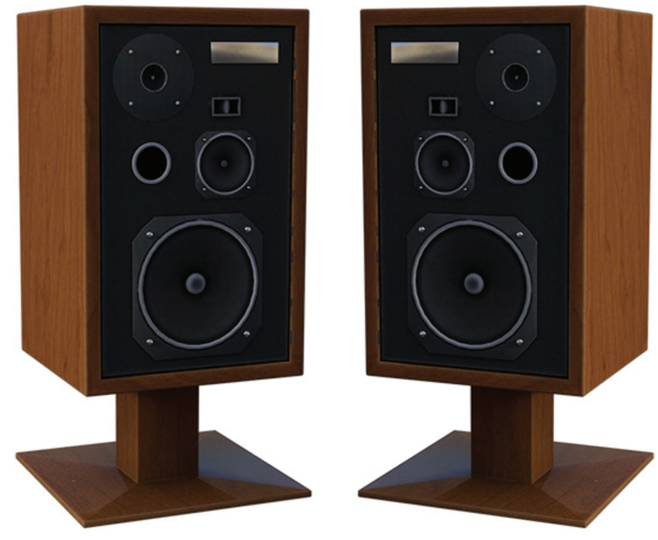

Fig. 4: Visual image for the word speakers in Example 6.

\section{References}

Abedi, Jamal (2002): Standardized achievement tests and English language learners:

Psychometrics issues. Educational Assessment 8 (3), 231-257.

Abedi, Jamal (2009): Computer testing as a form of accommodation for English language learners. Educational Assessment 14 (3/4), 195-211. 
Abedi, Jamal, Hofstetter, Carolyn Huie \& Lord, Carol (2004): Assessment accommodations for English language learners: Implications for policy-based empirical research. Review of Educational Research 74 (1), 1-28.

Abedi, Jamal \& Lord, Carol (2001): The language factor in mathematics tests. Applied Measurement in Education 14 (3), 219-234.

Adams, Mark James (1990): Beginning to Read: Thinking about Print. Cambridge: MIT Press.

Anderson, Richard \& Nagy, William (1991): Word meanings. In Barr, Rebecca, Kamil, Michael, Mosenthal, Peter, David Pearson, P. (Eds.): The Handbook of Reading Research, Volume II. Mahwah, N): Lawrence Erlbaum Associates, 690-724.

Anderson, Richard, Pichert, James, Goetz, Ernest, Diane. L., Schallert, Stevens, Kathleen \& Trollip, Stanley (1976): Instantiation of general terms. Journal of Verbal Learning and Verbal Behavior 15 (6), 667-679.

August, Diane \& Shanahan, Timothy (Eds.) (2006): Developing Literacy in Second-language Learners: Report of the National Literacy Panel on Language Minority Children and Youth. Mahwah, NJ: Lawrence Erlbaum Associates.

Beck, Isabel \& McKeown, Margaret (1991): Conditions of vocabulary acquisition. In Barr, R., Kamil, M., Mosenthal, P., Pearson, P. (Eds.): Handbook of Reading Research Volume II. Mahwah, NJ: Lawrence Erlbaum Associates, 789-814.

Blau, Eileen (1982): The effect of syntax on readability for ESL students in Puerto Rico. TESOL Quarterly 16, 517-528.

Cook, Gary \& MacDonald, Rita. 2013. Tool to Evaluate Language Complexity of Test Items (WCER Working Paper No. 2013-5). Retrieved from University of Wisconsin- Madison, Wisconsin Center for Education Research website: http://www.wcer.wisc.edu/publica tions/workingPapers/papers.php

Crowhurst, Marion (1994): Language and Learning across the Curriculum. Scarborough, Ontario: Allyn and Bacon.

Davison, Alice \& Kantor, Robert (1982): On the failure of readability formulas to define readable texts: A case study from adaptations. Reading Research Quarterly 17 (2), 187-209.

Negueruela, Eduardo, Lantolf, James, Jordan, Stefanie \& Gelabert, Jaime (2004): The "private function" of gesture in second language speaking activity: A study of motion verbs and gesturing in English and Spanish. International Journal of Applied Linguistics 14, 113-147.

Gentner, Deirdre (1982): Why nouns are learned before verbs: Linguistic relativity versus natural partitioning. In Kuczaj, S. (Ed.): Language Development: Language, Cognition and Culture. Hillsdale, N.J.: Lawrence Erlbaum Associates Inc, 301-334.

Gentner, Deirdre (2006): Why verbs are hard to learn. In Gentner, D. (Ed.): Action Meets Word: How Children Learn Verbs. New York: Oxford University Press, 544-564.

Graves, Michael, August, Diane \& Mancella-Martinez, Jeanette (2012): Teaching Vocabulary to English Langue Learners. New York: Teachers College Press.

Halliday, Michael (1975). Some aspects of sociolinguistics, in E. Jacobsen (Ed.), Interactions Between Linguistics and Mathematics Education: Final report of the symposium sponsored by UNESCO, CEDO, and ICMI; Nairobi, Kenya, September 11-14, 1974. UNESCO Report No. ED-74/CONF.808). Paris, UNESCO, 64-73.

Hiebert, E. H., Scott, J. A., Castaneda, R. \& Spichtig, A. (2019): An analysis of the features of words that influence vocabulary difficulty. Education Sciences 9 (1), 8.

Hirigoyen, Héctor (1997): Dialectical variations in the language of mathematics: A source of multicultural experiences. In Trentacosta, J., Kenney, M. J. (eds): Multicultural and Gender 
Equity in the Mathematics Classroom: The Gift of Diversity-1997 Yearbook. Reston, VA: NCTM, 164-168.

Landau, Sidney (1984): Dictionaries: The Art and Craft of Lexicography. New York: Charles Scribner's Sons.

Manyak, Patrick (2012): Powerful vocabulary instruction for English learners. In Kame'enui, E., Baumann, J. (Eds.): Vocabulary Instruction: From Research to Practice, 2nd Ed. New York: Guilford Press, 280-302.

Martiniello, Maria (2008): Language and the performance of English language learners in math word problems. Harvard Educational Review 78 (2), 333-368.

Martiniello, Maria (2009): Linguistic complexity, schematic representations, and differential item functioning for English language learners in math tests. Educational Assessment 14 (3), 160-179.

Martiniello, Maria \& Wolf, Mikyung Kim. (2012): Exploring ELLs’ understanding of word problems in mathematics assessments: The role of text complexity and student background knowledge. In Celedón-Pattichis, S., Ramirez, N. (Eds.): Beyond Good Teaching: Strategies that are Imperative for English Language Learners in the Mathematics Classroom. Reston, VA: NCTM, 151-162.

McKeown, Margaret (1993): Creating definitions for young word learners. Reading Research Quarterly 28, 16-33.

McNamara, Timothy, Miller, Diana \& Bransford, John (1991): Mental models and reading comprehension. In Barr, R., Kamil, M., Mosenthal, P., Pearson, P. D. (Eds.): The Handbook of Reading Research, Mahwah, NJ: Lawrence Erlbaum Associates, 490-511.

Mesmer, Heidi, Cunningham, James \& Hiebert, Elfrieda (2012): Toward a theoretical model of text complexity for the early grades: Learning from the past, anticipating the future. Reading Research Quarterly 47, 235-258.

Miller, George \& Gildea, Patricia (1987): How children learn words. Scientific American 2573, 94-99.

Moschkovich, Judit (2007): Examining mathematical discourse practices. For the Learning of Mathematics 27 (1), 24-30.

Nagy, William (2009): Understanding words and word learning: Putting research on vocabulary into classroom practice. In Rosenfield, S., Berninger, V. (Eds.): Implementing Evidencebased Academic Interventions in School Settings. New York: Oxford University Press, 479-500.

Nagy, William, García, G. E., Durgunoğlu, A. Y. \& Hancin-Bhatt, B. (1993): Spanish-English bilingual students' use of cognates in English reading. Journal of Literacy Research 25 (3), 241-259.

Nagy, William \& Hiebert, Elfrieda (2011): Toward a theory of word selection. In Michael Kamil, P., Pearson, David, Moje, Elizabeth, Afflerbach, Peter (Eds.): Handbook of Reading Research, Volume IV. New York: Routledge, 388-404.

Nagy, William \& Scott, Judith (2000): Vocabulary processes. In Kamil, Michael, Peter Mosenthal, P., Pearson, David, Barr, Rebecca (Eds.): Handbook of Reading Research: Volume III. Mahwah, NJ: Erlbaum, 269-284.

O’Halloran, Kay L. (2005): Mathematical Discourse: Language, Symbolism and Visual Images. London, England: Continuum.

Peregoy, Suzanne \& Boyle, Owen. F. (2000): English learners reading English: What we know, what we need to know. Theory into Practice 39 (4), 237-247. 
Pimm, David (1987): Speaking Mathematically: Communication in Mathematics Classrooms. London: Routledge \& Kegan Paul.

Rand Reading Study Group (2002): Reading for understanding: Toward a research and development program in reading comprehension. Prepared for the Office of Educational Research and Improvement. Washington, DC: US Department of Education.

Sato, Edynn, Rabinowitz, Stanley, Carole, Gallagher \& Huang, Chun-Wei. 2010. Accommodations for English language learner students: The effect of linguistic modification of math test item sets. (Final Report. NCEE 2009-4079) National Center for Education Evaluation and Regional Assistance National Center for Education Evaluation and Regional Assistance.

Scott, Judith \& Nagy, William (1997): Understanding the definitions of unfamiliar verbs. Reading Research Quarterly 32 (2), 184-200.

Shaftel, Julia, Belton-Kocher, Evelyn, Glasnapp, Douglas \& Poggio, John (2006): The impact of language characteristics in mathematics test items on the performance of English language learners and students with disabilities. Educational Assessment 11 (2), 105-126.

Walkerdine, Valerie (1988): The Mastery of Reason: Cognitive Development and the Production of Rationality. London: Routledge.

Zeno, Susan, Ivens, Stephan, Millard, Robert \& Duvvuri, Raj. (1995): The Educator's Word Frequency Guide. New York: Touchstone Applied Science Associates. 